\title{
Geometric Parameters Design and Shear Buckling Strength Research of the Type 3200 Corrugated Steel Webs
}

\author{
Jiawei Sun, Yong Wang and Shui Wan \\ Guangdong Nanyue Transportation Investment \& Construction Co.Ltd, Guangzhou, Guangdong \\ Southeast University, Nanjing, Jiangsu \\ Southeast University, Nanjing, Jiangsu \\ 691331101@qq.com, 1096011798@qq.com, lanyu421@163.com
}

\begin{abstract}
Keywords: the type 3200 corrugated steel webs; shear buckling; geometric parameters; finite element method

Abstract. The prestressed concrete composite box girder bridge with corrugated steel webs is a new type of bridge structure which has been widely used in China in recent years. This paper summarizes the development of corrugated steel webs elastic shear buckling strength theory and the corresponding methods. In order to meet the practical engineering requirements of the large height girder bridge with corrugated steel webs, the geometric parameters of the type 3200 corrugated steel webs were preliminarily designed. A reliable finite element model for the analysis of elastic shear buckling of corrugated steel webs was established, and the type 3200 corrugated steel webs were checked by finite element method.
\end{abstract}

\section{Introduction}

The most remarkable feature of the prestressed concrete composite girder bridge with corrugated steel webs is that the corrugated steel webs replace the concrete webs, which makes the box girders a composite structure composed of reinforced concrete and corrugated steel webs. Because the corrugated steel webs replace the concrete web, the weight of the PC box girder is reduced, thus reducing the volume of the substructure and reducing the cost. The data show that compared with the prestressed concrete bridge of the same span, the PC composite box girder bridge with corrugated steel webs can save about $10 \%$ of the cost. Since the PC composite box beam of corrugated steel webs is relatively light, the length of each construction section can be increased by shortening the length of each construction section, thus shortening the construction period.

Look from the structure, the PC composite box girder bridge with corrugated steel webs has clear mechanical behavior, under the effect of the axial force and bending moment, the axial stress of the webs is essentially zero, the axial force is bore by the top and bottom concrete; the $87 \%$ shear effect and the $75 \%$ torque action are bore by the corrugated steel webs. The corrugated steel web has no resistance to the axial force and avoids the reduction of the prestressing force without the constraint action of the web. Therefore, the prestressed force can be more effectively applied to the top and the bottom of the concrete. Because the corrugated steel webs do not restrain the deformation caused by shrinkage and creep of the top and bottom concrete of the box girder, the prestress force of the box girder section is forbidden to transfer to the steel webs. The steel plate is used as the web to avoid the oblique cracking of the traditional concrete web and improve the durability. Compared with the prestressed concrete box girder, the torsional stiffness of the PC composite box girder of corrugated steel webs decreases by about $60 \%$ [1-4].

Corrugated steel webs are generally bent from coils or sheets. Trapezoidal corrugated plate was commonly used in the practical engineering and its geometry was shown as follows. 


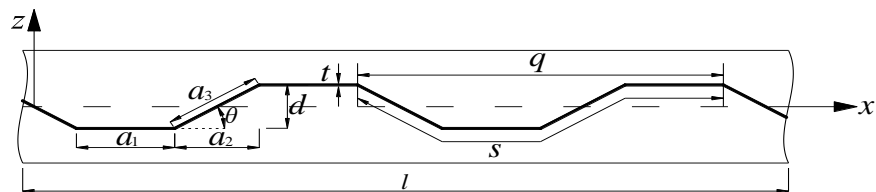

Figure.1.Geometric parameters of trapezoidal corrugated plate.

Table 1. Geometric parameters of common used trapezoidal corrugated plate.

\begin{tabular}{ccccccc}
\hline \multirow{2}{*}{ Type } & \multicolumn{4}{c}{ Geometric $(\mathrm{mm})$} & \multicolumn{2}{c}{ Angle } \\
& $q$ & $a_{1}$ & $a_{2}$ & $a_{3}$ & $d$ & $\Theta$ \\
\hline 1000 & 1000 & 340 & 160 & 226 & 160 & 45.07 \\
1200 & 1200 & 330 & 270 & 336 & 200 & 36.53 \\
1600 & 1600 & 430 & 370 & 430 & 220 & 30.77 \\
\hline
\end{tabular}

\section{Elastic buckling characteristics of corrugated steel webs}

The analysis of shear buckling is an important content of the design of corrugated steel webs. In the stability of the plates, there are two basic buckling modes: bifurcation point buckling and extreme point buckling. The critical load of bifurcation buckling is defined as the ultimate load that keeps the structure in a stable equilibrium state. When the load reaches the critical load, any minor perturbation will cause a significant buckling deformation of the member, leading to the collapse of the structure. In this kind of buckling process, the stress state of the structure is changed from the stress state of the film before buckling to the obvious bending stress state. The buckling process of corrugated steel webs is a typical structural bifurcation point buckling.

The local buckling force of the corrugated steel webs is shown in Figure 2. The geometric parameters in the figure are the height of the corrugated steel webs, the maximum width of the twist section of the corrugated steel webs $\left(a=\max \left(a_{1}, a_{2}\right)\right.$ and the thickness of the steel plate. After the height of corrugated steel webs is determined, the local buckling strength of corrugated steel webs can be changed by adjusting the length and the thickness of the corrugated steel webs.

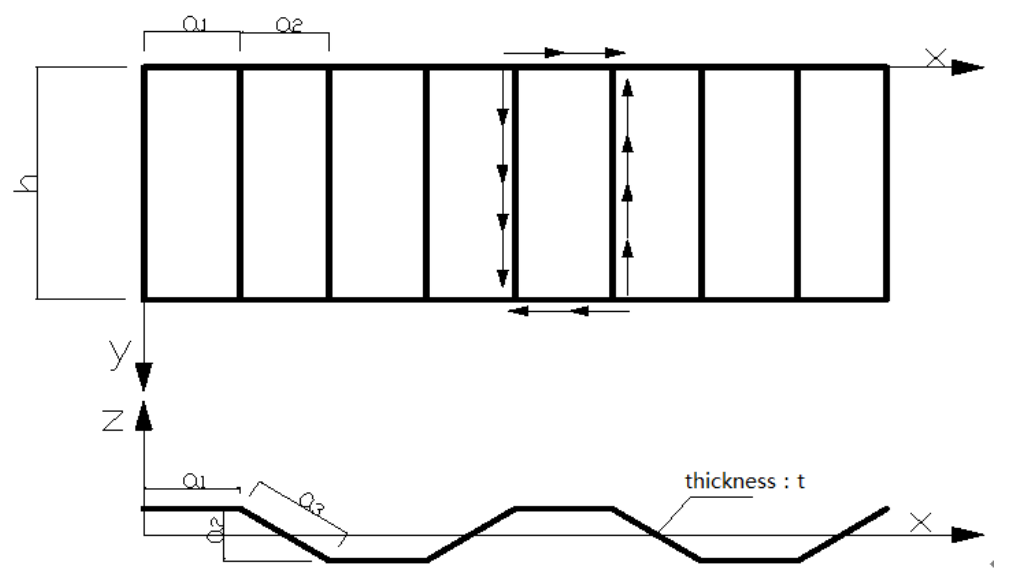

Figure.2. The local buckling force of corrugated steel webs

The global buckling mode of a corrugated steel web is similar to the buckling mode observed in a flat orthotropic plate when the corrugated steel web is simulated as an equivalent flat orthotropic plate. This mode is critical in webs with shallow folds. The corresponding critical buckling stress can be calculated based on the orthotropic plate buckling theory. 


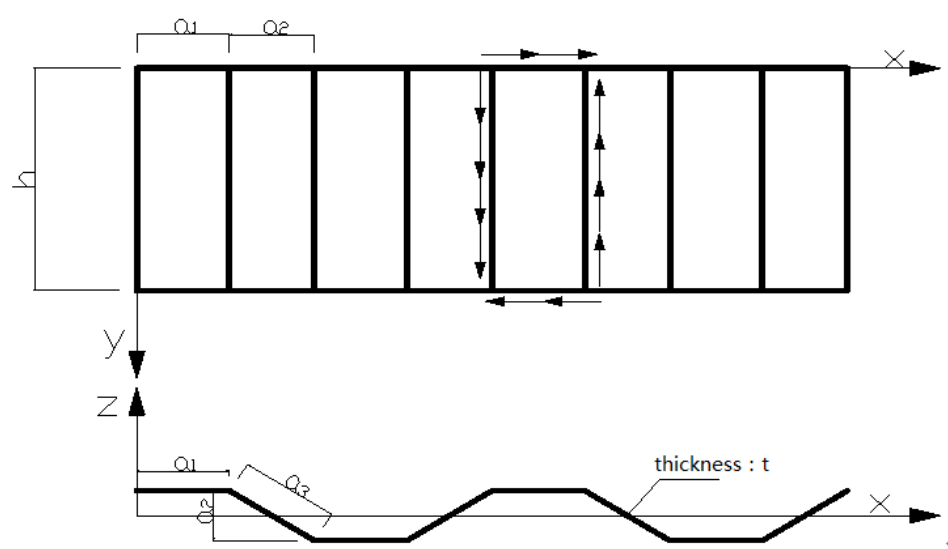

Figure.3. The global buckling force of corrugated steel webs

An interactive buckling mode results from the interaction between the local and global buckling modes, and it is also the most difficult buckling mode to predict. Previous research work has shown that the buckling failure of corrugated web is mainly governed by interactive shear buckling. However, the causes of interactive shear buckling have not been fully understood, with much of the research work conservatively underestimating the shear buckling strength.

\section{Parametric design of the type 3200 corrugated steel webs under inelastic buckling}

In order to achieve economic rationality, the principle of the design is controlling buckling in yield or inelastic. The buckling stress is in the inelastic region, as $\lambda_{s} \leq \sqrt{2}$ ( $\lambda_{s}$ is the coefficient of shear buckling, $\lambda_{s}=\sqrt{\tau_{y} / \tau_{c r, l}^{\mathrm{e}}}$ ) , but it is more desirable to make full use of the material as $\lambda_{s} \leq 0.6$.

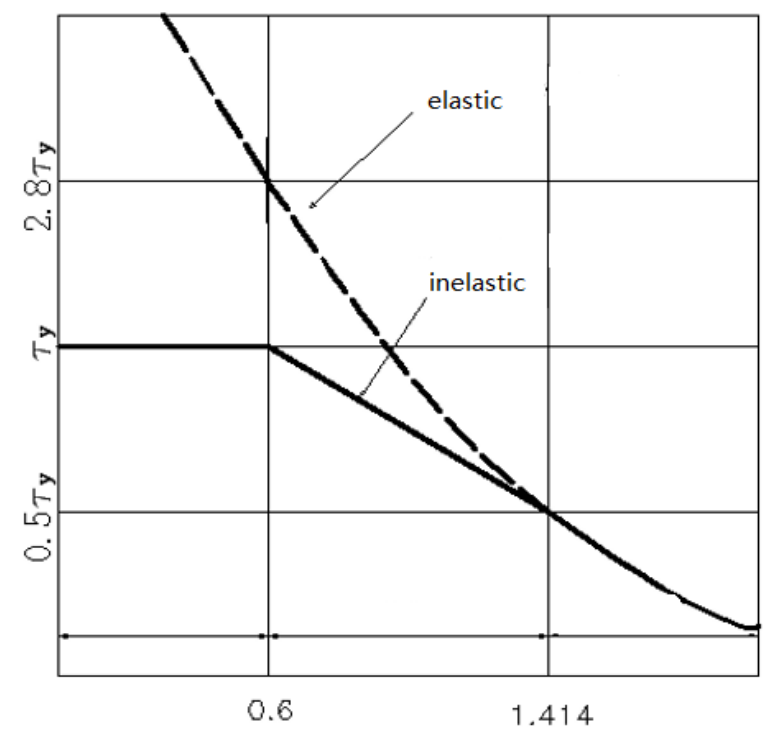

Figure.4. Inelastic shear buckling strength is considered

In the design guideline of Japan [5], the shear buckling coefficient as $\lambda_{s}=\sqrt{\tau_{y} / \tau_{c r, l}}$, the formula for calculating the buckling stress of corrugated steel webs is given as

$$
\begin{aligned}
& \left\{\begin{array}{l}
\tau_{c r}=\tau_{y} \\
\tau_{c r}=\tau_{y}\left[1-0.614\left(\lambda_{s}-0.6\right)\right] \\
\tau_{c r}=\tau_{y} / \lambda_{s}^{2}
\end{array}\right. \\
& \lambda_{s} \leq 0.6 \\
& 0.6 \leq \lambda_{s} \leq \sqrt{2} \\
& \lambda_{s} \geq \sqrt{2}
\end{aligned}
$$

where $\tau_{y}=$ shear flow limit for materials.

The shape factor of corrugated steel webs is generally about 0.9 , and the folding angle is generally between 30 and 45 degrees. If the material performance of corrugated steel webs is most effective, the 
critical shear stress of buckling is in the yield domain, when $\lambda_{\mathrm{s}} \leq 0.6$, the data indicate that the strength of the design is controlled by strength and that the design is relatively safe. When the geometric parameters and yield strength of the steel plate are substituted into the formula (2), the buckling critical force can be obtained and the amplitude width requirement in the yield domain can be controlled:

where

$$
\begin{cases}a \leq \mathrm{h}_{w} & t_{w} / h_{w} \geq 1 / k_{1} \\ a \leq \frac{t_{w}}{0.865 \sqrt{1 / k_{1}^{2}-\gamma^{2}}} & t_{w} / h_{w}<1 / k_{1}\end{cases}
$$

Taking E=2.06 x $10^{5} \mathrm{MPa}, \mathrm{v}=0.31, \mathrm{f}_{\mathrm{vd}}=160 \mathrm{MPa}$, thus $k_{1}=56.6$,

$$
\begin{cases}a \leq \mathrm{h}_{w} & t_{w} \geq 0.018 h_{w} \\ a \leq 65.4 t_{w} & t_{w}<0.018 h_{w}\end{cases}
$$

In engineering practice, for the development of the new high corrugated steel webs, in order to ensure the reasonable design, the height $h_{w}$ of corrugated steel webs is larger the thickness is as $t_{w}<0.018 h_{w}$,

$$
a \leq 65.4 t_{w}
$$

The global buckling is the same as the local buckling. If the global buckling strength is required to be in the yield domain, the control condition $\lambda_{\mathrm{s}} \leq 0.6$ is also obtained, and the relevant parameters are substituted by the relevant formulas:

where

$$
\mathrm{d} \geq t_{w} \sqrt{\left[h_{w} /\left(k_{2} t_{w}\right)\right]^{\frac{8}{3}}-1}
$$

$$
k_{2}=\frac{3.6(E \beta)^{1 / 2}}{\left(f_{v d}\right)^{1 / 2}\left[12\left(1-v^{2}\right)\right]^{1 / 8}(6 \eta)^{3 / 8}}
$$

Similarly, taking $\mathrm{E}=2.06 \times 10^{5} \mathrm{MPa}, \mathrm{v}=0.31, \mathrm{f}_{\mathrm{vd}}=160 \mathrm{MPa}$, thus $k_{2}=50.3$,

$$
\mathrm{d} \geq t_{w} \sqrt{\left[h_{w} /\left(50.3 t_{w}\right)\right]^{\frac{8}{3}}-1}
$$

Thickness-height ratio $(\gamma=t / h)$ of the corrugated steel webs is used as abscissa, width-height ratio $(\alpha=a / h)$ is used as ordinate, the local shear buckling limit diagram of corrugated steel webs can be obtained (Figure.5). Thickness-height ratio $(\gamma=t / h)$ of the corrugated steel webs is used as abscissa, ratio of wave height to plate thickness $(\delta=d / t)$ is used as ordinate, the global shear buckling limit diagram of corrugated steel webs can be obtained (Figure.6). 


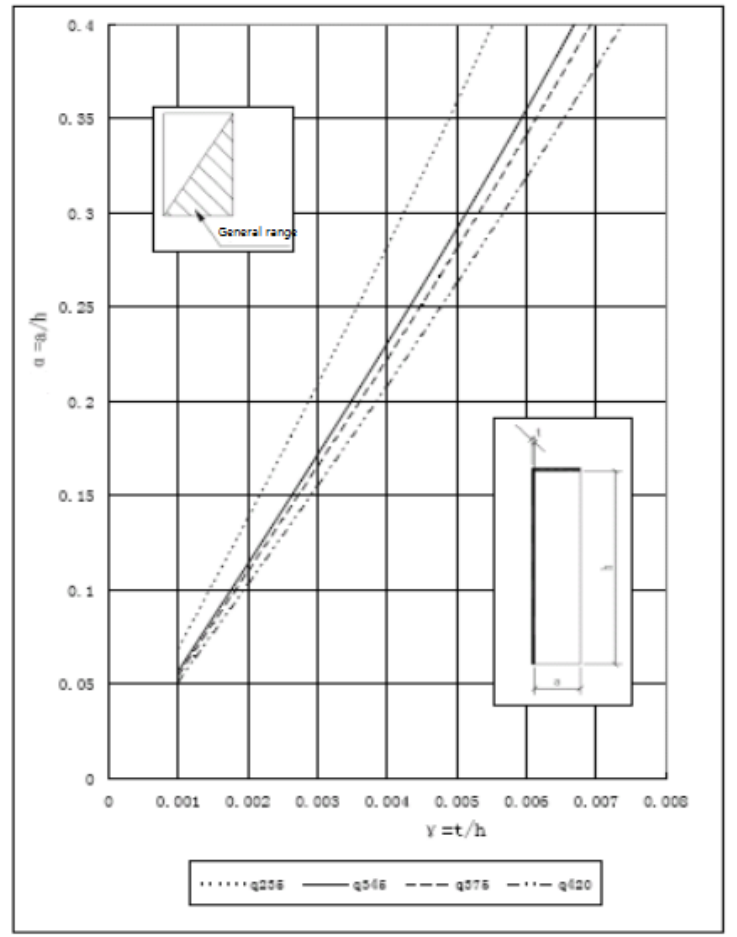

Fig. 5 The local shear buckling limit

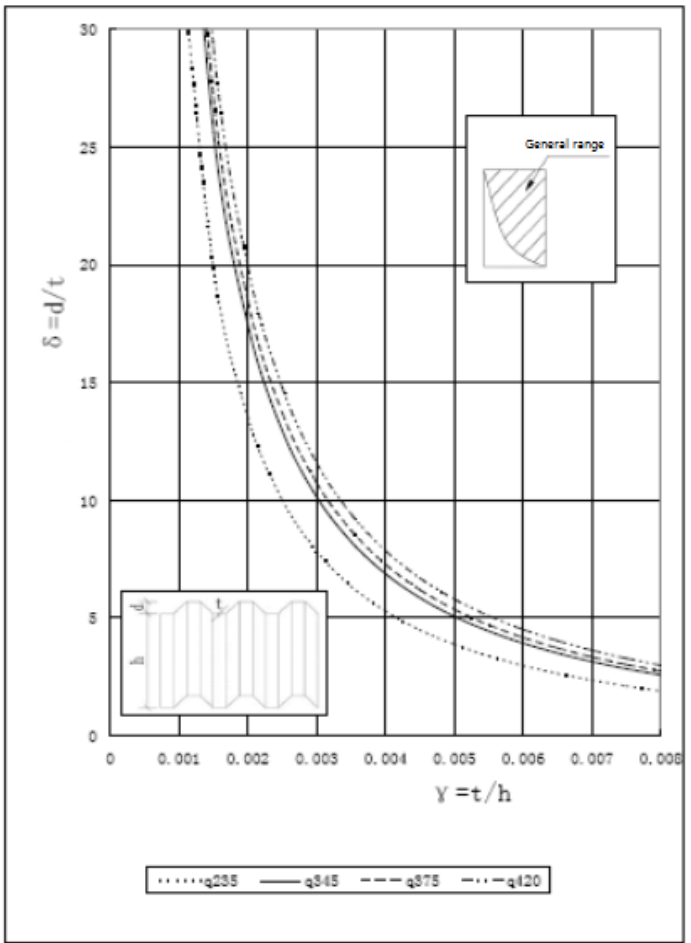

Fig. 6 The global shear buckling limit

Combining with the foregoing analysis, it is worth noticing that the design should avoid using the height and thickness of corrugated steel webs that does not meet the requirement, we can draft the preliminary geometric parameters of type 3200 corrugated steel webs as follows.

Table 2 Geometrical dimensions of the 3200 corrugated steel webs

\begin{tabular}{ccccccc}
\hline \multirow{2}{*}{ Type } & \multicolumn{4}{c}{ Geometric (mm) } & \multicolumn{3}{c}{ Angle } \\
& $q$ & $a_{1}$ & $a_{2}$ & $a_{3}$ & $d$ & $\theta$ \\
\hline 3200 & 3200 & 860 & 740 & 860 & 438 & 30.6 \\
\hline
\end{tabular}

\section{Comparison of finite element calculation and theoretical formula of the type 3200 corrugated steel webs}

In order to study the elastic shear buckling performance, the software of finite element analysis was adopted to establish the finite element model of corrugated steel webs. Once the corrugated steel webs bending deformation occurred, they had the characteristics of the curved shell, so the SHELL181 element which considerated the shear deformation was used to discretize the corrugated steel webs. The element of SHELL181 had 4 nodes and every node had 6 degrees of freedom, which were the translational degrees of freedom along the $\mathrm{X}, \mathrm{Y}, \mathrm{Z}$ direction and the rotation degrees of freedom around the $\mathrm{X}, \mathrm{Y}$, and $\mathrm{Z}$ axis. In addition, the SHELL181 element had the capacity of plasticity, stress stiffness, large deformation and large strain.

The finite element model of the type 3200 corrugated steel webs was shown in Figure.6, the density of grid ensured that the results of analysis can be stable. 


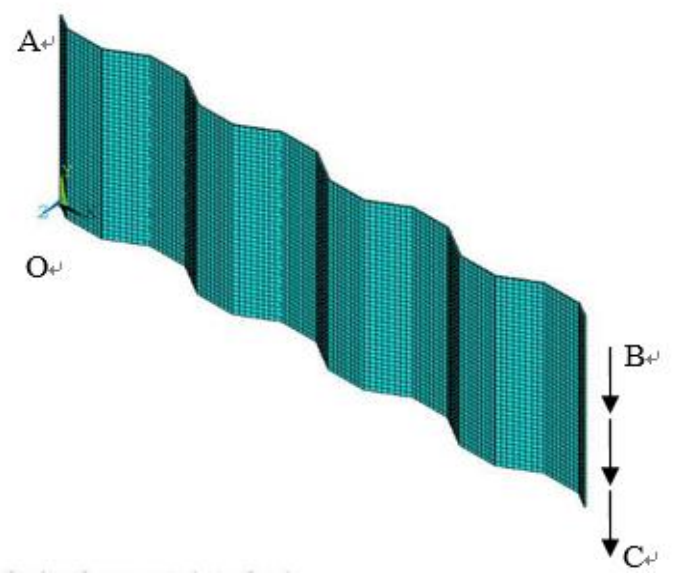

Figure.7.The finite element model of corrugated steel webs.

To study the buckling performance of the corrugated steel webs, we didn't consider the upper and lower flange and the stiffening plate influence. The boundary conditions were simply supported edges and shown as table3 [6-8].

Table3.The boundary conditions about the finite element model of corrugated steel webs.

\begin{tabular}{ccccccc}
\hline \multirow{2}{*}{ Boundary } & $\mathrm{Ux}$ & Translational degrees & $\mathrm{Uy}$ & $\mathrm{Uz}$ & $\mathrm{Rx}$ & Rotation degrees \\
& $\mathrm{R}$ & $\mathrm{R}$ & $\mathrm{R}$ & $\mathrm{F}$ & $\mathrm{F}$ & $\mathrm{Rz}$ \\
\hline $\mathrm{OA}$ & $\mathrm{R}$ & $\mathrm{F}$ & $\mathrm{R}$ & $\mathrm{F}$ & $\mathrm{F}$ & $\mathrm{F}$ \\
$\mathrm{AB}$ & $\mathrm{R}$ & $\mathrm{F}$ & $\mathrm{R}$ & $\mathrm{F}$ & $\mathrm{F}$ & $\mathrm{F}$ \\
$\mathrm{BC}$ & $\mathrm{R}$ & $\mathrm{F}$ & $\mathrm{R}$ & $\mathrm{F}$ & $\mathrm{F}$ & $\mathrm{F}$ \\
$\mathrm{CO}$ & & & &
\end{tabular}

F: Free. R: Restrained.

In order to keep corrugated steel webs occurring shear buckling failure mode, when exerting uniform shear loading at the edge of the $\mathrm{BC}$, it can be thought that corrugated steel webs were in a state of pure shear stress.

Table4. Comparison between finite element and formulas results.

\begin{tabular}{|c|c|c|c|c|c|c|c|}
\hline \multirow{2}{*}{ No. } & \multirow{2}{*}{$h_{\mathrm{w}}(\mathrm{mm})$} & \multirow{2}{*}{$t_{\mathrm{w}}(\mathrm{mm})$} & \multicolumn{2}{|c|}{ Finite } & \multicolumn{2}{|c|}{ Formulas } & \multirow{2}{*}{$\tau_{\mathrm{cr}} / \tau_{\mathrm{cr}, \mathrm{FEM}}$} \\
\hline & & & $\tau_{\mathrm{cr}, \mathrm{FEM}}(\mathrm{MPa})$ & Modle & $\tau_{\mathrm{c}, \mathrm{FEM}}(\mathrm{MPa})$ & Modle & \\
\hline 1 & 4000 & 25 & 791.94 & 1 & 869.26 & 1 & 0.91 \\
\hline 2 & 4000 & 35 & 1471.52 & 1 & 1703.76 & 1 & 0.86 \\
\hline 3 & 5000 & 25 & 786.02 & 1 & 858.79 & 1 & 0.92 \\
\hline 4 & 5000 & 35 & 1461.06 & $\mathrm{i}$ & 1600.58 & $\mathrm{i}$ & 0.91 \\
\hline 5 & 6000 & 25 & 744.74 & 1 & 828.31 & 1 & 0.90 \\
\hline 6 & 6000 & 35 & 1399.32 & i & 1417.87 & $\mathrm{i}$ & 0.99 \\
\hline 7 & 7000 & 25 & 702.2 & $\mathrm{i}$ & 777.96 & $\mathrm{i}$ & 0.90 \\
\hline 8 & 7000 & 35 & 1090.96 & i & 1166.45 & $\mathrm{i}$ & 0.94 \\
\hline 9 & 8000 & 25 & 644.46 & i & 694.42 & $\mathrm{i}$ & 0.93 \\
\hline 10 & 8000 & 35 & 858.44 & i & 932.05 & $\mathrm{i}$ & 0.92 \\
\hline 11 & 9000 & 25 & 533.94 & i & 594.38 & $\mathrm{i}$ & 0.90 \\
\hline 12 & 9000 & 35 & 819.08 & i & 747.96 & $\mathrm{i}$ & 1.10 \\
\hline 13 & 10000 & 25 & 509.94 & i & 499.69 & $\mathrm{i}$ & 1.02 \\
\hline 14 & 10000 & 35 & 629.84 & i & 609.46 & $\mathrm{i}$ & 1.03 \\
\hline
\end{tabular}

As can be seen from the Table4, the formulas calculation results were in good agreement with the finite element results, and according to the formula calculation results, it can accurately determine the corrugated steel webs buckling mode, which could guide the design of the type 3200 corrugated steel webs. 


\section{Conclusion}

With the span of the prestressed concrete composite box girder bridge with corrugated steel webs is increasing, the height is also higher, using the theoretical formula of local buckling strength, global buckling strength and interactive buckling strength to control the strength, we drafted the preliminary geometric parameters of the type 3200 corrugated steel webs and built finite element. The result shows that the design of the type 3200 corrugated steel webs is reasonable and provides a reference for practical engineering.

\section{Acknowledgements}

This work was financially supported by the Guangdong Nanyue Transportation Investment \& Construction Co.Ltd.

\section{References}

[1]王福敏. 钢腹板预应力混凝土组合箱梁桥的发展及其应用现状 [J]. 公路交通技术. 1999(02): 62-65.

[2] Rosignoli M. Prestressed concrete box girder bridges with folded steel plate webs[J]. Proceedings of the Institution of Civil Engineers. Structures and Buildings. 1999, 134(1): 77-85.

[3] 刘岗, 崔铁万. 本谷桥的设计与施工一一采用悬臂架设施工法的波纹形钢腹板预应力混凝 土箱梁 $[J]$. 国外桥梁. 1999(3): 18-25.

[4] 黄炳生, 蒋萌, 庄晖. 波纹腹板钢梁研究与应用进展 [J]. 南京工业大学学报 (自然科学版). 2010(5): 100-105.

[5] 波形鋼板ウェブ橋合成構造研究会. 波形鋼板ウェブPC橋計画マニュアル（案）[M]. 1998. [6] Yi J, Gil H, Youm K, et al. Interactive shear buckling behavior of trapezoidally corrugated steel webs[J]. Engineering Structures. 2008, 30(6): 1659-1666.

[7] Eldib M. Shear buckling strength and design of curved corrugated steel webs for bridges[J]. Journal of Constructional Steel Research. 2009, 65(12): 2129-2139.

[8] Nie J, Zhu L, Tao M, et al. Shear strength of trapezoidal corrugated steel webs[J]. Journal of Constructional Steel Research. 2013, 85: 